\title{
Correspondence
}

\section{Psychotherapy via Skype: a therapist's experience}

There are some who think that psychodynamic psychotherapy has not or will not move with the times. Perhaps because of this attitude and it not being seen as a cost-effective treatment, services have recently been decommissioned in the National Health Service (NHS). ${ }^{1}$

There is an ever-increasing number of people delivering psychotherapies over the internet. You only have to google 'internet psychotherapy' for a plethora of websites to appear providing you with access to online material and 'face-to-face time' with a therapist. There is, however, very little research into the delivery of psychodynamic psychotherapy via the internet. The vast majority of studies to date have investigated the effectiveness of cognitive-behavioural therapy delivered by modern communication, ${ }^{2}$ predominantly self-guided or by telephone, but even this research is scant. An article by Fishkin et $a l^{3}$ discusses how for several years the China American Psychoanalytic Alliance (CAPA) has provided treatment, training and supervision via the internet using Skype, which they have found to be a practical and successful alternative to traditional methods, and which has been instrumental in improving access to training and therapy for Chinese mental health professionals.

I was almost halfway through my year-long psychodynamic psychotherapy sessions with a patient when he told me that he was moving to a different city and so would no longer be able to attend. We were both disappointed; sessions had been going well and we had developed a good relationship. The patient suggested 'meeting halfway' but this was not practical and we concluded that his therapy with me would have to end.

At my next supervision I delivered the news to my supervisor who, much to my surprise, suggested carrying on via Skype. When I mentioned this to the patient at our next session he was very happy to give it a go.

Before the first internet session, I had tested it out with a friend to ensure I had the right lighting and environment at my end. The patient would be in his own home. I was quite intrigued by the fact that the patient, who had reliably been about 10 minutes late for the majority of our face-to-face sessions, was also 10 minutes late for his Skype session, and for many of the subsequent sessions too. It took a few minutes to get going but it was actually surprisingly easy to adjust.

The patient instantly appeared more relaxed and appeared to speak more openly and frankly with me, which continued throughout our Skype sessions. Was this a consequence of him being in the comfort of his own home, or perhaps not being in the same room was less intimidating?

Something that was quite disconcerting was trying to make eye contact; the positioning of the cameras meant that for both of us, looking directly at the other's face on the screen would mean that eye contact was not being made. I would sometimes try to compensate for this by looking directly into the camera but this felt false and I would not be able to tell whether he was returning my eye contact. However, by discussing these difficulties and the nuances of Skype, this did not appear to hinder our sessions.
Silences and active listening suddenly became a new experience to negotiate. Any prolonged pauses would cause me to worry that the connection had been lost, and clearly this was also the patient's concern as we would both on occasion say, 'Are you still there?' Similarly, I also found myself nodding in an exaggerated manner and making louder and more frequent listening noises to convey to the patient that I was still connected, both technically and mentally.

A few sessions were blighted by technological problems: the sound would not sync with the picture or it would cut out altogether, the patient's face would become a hazy blur and sometimes the connection would be lost several times, making for a rather disjointed session. There did seem to be a correlation between these technically difficult sessions and psychotherapeutically challenging sessions. From my notes of these particular sessions, I detected in the countertransference a sense of frustration, often before any technological difficulties ensued; however, this is likely to be only coincidence.

For the final session we met in person again, which felt like a more appropriate way to end. I had not seen the patient in the flesh for over 6 months and so felt slightly apprehensive as to what it would be like. It actually felt 'normal', which I believe is a reflection of the effectiveness of the Skype sessions at maintaining and building on our already established therapistpatient relationship. This phenomenon is also mentioned by Lana Fishkin ${ }^{3}$ : part-way through the analysis with her patient she was able to meet him in person in China. Both she and the patient commented that it did not feel different from their Skype sessions.

Overall, I think that being able to continue our sessions via Skype was incredibly useful for both the patient and me. It meant that those that we had before he moved were not a waste of our time and of course this had a positive financial implication for the psychotherapy service too.

In both my and the patient's opinion the therapy had been successful. This was also reflected in the outcome measures (the CORE outcome measure tool): the patient showed a significant improvement in all domains of well-being, symptoms, functioning and risk, which was also sustained at a 6-month review. What impact the use of Skype had on the level of improvement is, however, uncertain: the effectiveness of psychodynamic psychotherapy via Skype compared with being in the same room with the patient is an area for further investigation if this method is to be taken seriously.

I believe that there is a role for Skype or other distance communication technologies in delivering psychological therapies. I think my successful use of Skype was facilitated by having already developed a rapport and a good relationship with the patient over several sessions in person, although Fishkin et $a^{3}$ did not report any negative sequelae of not having met their patients in person before starting therapy. The use of such modern forms of communication could, and does, have a role in improving access to psychotherapies for people living in remote areas and also for people who might be housebound. The role of online therapy delivery is expanding and is likely to 
continue to do so. For this expansion to be successful further investigation into its effectiveness is warranted.

1 Fonagy $\mathrm{P}$, Lemma A. Does psychoanalysis have a valuable place in modern mental health services? Yes. BMJ 2012; 344: e1211.

2 Bee P, Bower P, Lovell K, Gilbody S, Richards D, Gask, L, et al. Psychotherapy mediated by remote communication technologies: a meta-analytic review. BMC Psychiatry 2008; 8: 60 .

3 Fishkin R, Fishkin L, Leli U, Katz B, Snyder E. Psychodynamic treatment, training, and supervision using internet-based technologies. J Am Acad Psychoanal Dyn Psychiatry 2011; 39: 155-68.

Francesca L. Bell MRCPsych, CT3 in psychiatry, Camden Psychodynamic Psychotherapy Service, Camden and Islington NHS Foundation Trust, London, UK, email: franbell@doctors.org.uk

doi: $10.1192 / p b .37 .4 .144$

\section{Teaching undergraduate psychiatry in a forensic setting}

Typically, medical students do not learn about psychiatry in forensic settings. Depending on their interests and their medical school, they might have access to special study modules or elective placements in their final year. We introduced undergraduate psychiatry placements at our regional forensic service in New Zealand and surveyed the experiences and attitudes of our students over the past 2 years. The placement includes experience of medium-secure in-patients, community, prison and court liaison services.

McGauley \& Campbell ${ }^{1}$ asked whether medical students needed to know anything about forensic psychiatry and concluded that forensic psychiatry taught students about managing chronic illness, working with complex patients, understanding stigma and security, learning about personal and organisation dynamics and experiencing multidisciplinary, cross-disciplinary and multi-agency working. Such issues are relevant to all psychiatric specialties and some areas of medicine.

The University of Otago Medical School, Dunedin, was the first to be established in New Zealand. There are about 270 students each year. Students study psychological medicine throughout the 2nd year, and 8-week attachments, divided between two different areas of psychiatry, are compulsory in the 4th year. Students attend placements as part of the clinical team and complete logbooks of experiences, including team working and ethics. They see patients and learn about the assessment, formulation and management of common mental health problems. They regroup for weekly medical school teaching and undertake an examination with written and practical components.

We designed an online survey, which the medical school emailed to our 15 students who had spent their psychiatry placement with our forensic service; 73\% (11 students) responded. They were asked about the expectations and experiences they had had, the disorders they had learnt about, what they had enjoyed and what could have been improved.

Interestingly, 27\% were anxious about starting their placement. Most students thought that they would be learning mainly about 'legal issues' and seeing patients in prison. Some had 'no idea' what to expect. All respondents gained experience of seeing patients with schizophrenia, bipolar disorder, drug and alcohol problems and the problems associated with psychological trauma and head injury. Over
$70 \%$ also gained experience of seeing patients with personality disorders. Depressive and anxiety disorders were less commonly encountered, with around half of students gaining experience of these. We learnt that about $27 \%$ of respondents felt unsafe at some point during their placement and subsequently introduced a first-day security and safety induction and distributed a leaflet explaining the nature of forensic services and the placement, which we were told was useful

All students were positive and stated that they had enjoyed their placements. Over $70 \%$ rated the placement as 'excellent'. They appreciated seeing patients in a variety of settings which included in-patient, community, prison and court, and gained experience of a variety of mental health problems. Some students remarked that the placement was one of the best they had done in their undergraduate training to date. Forensic settings can therefore provide useful and enjoyable experiences to students as they learn about psychiatry as undergraduates.

1 McGauley G, Campbell C. Do medical students need to know anything about forensic psychiatry? Crim Behav Ment Health 2004; 14 (suppl 1): S6-11.

John P. Jacques, Consultant Forensic Psychiatrist and Senior Clinical Lecturer, Regional Forensic Service, Southern District Health Board, Dunedin, New Zealand, email: johnjacques77@doctors.org.uk

doi: $10.1192 / p b .37 .4 .145$

\section{Recruitment into psychiatry is working, but we are responsible for maintaining the momentum}

It is no secret that psychiatry has always struggled to recruit adequate numbers of doctors. This has led to the Royal College of Psychiatrists launching its Recruitment Strategy, implemented by a recruitment team. Their targets are to increase recruitment to core psychiatric training, achieving a 50\% increase in applications and a 95\% fill rate by the end of their 5 -year campaign. It is therefore most encouraging to learn that those foundation year (FY) doctors who are exposed to psychiatric placements are almost ten times more likely to embark on a career in the specialty. BMJ Careers reports ${ }^{1}$ that $15 \%$ of those FY2 doctors who undertook psychiatry placements applied for core psychiatry training, as compared with a mere $1.8 \%$ of those with no psychiatry exposure during their Foundation Programme. At last, a reason for quiet optimism, perhaps.

However, if we are to succeed in helping the College achieve its targets, it is clear that supervising clinicians have an important role to play. Archdall et al's qualitative study assessing medical students' perspectives of psychiatry postattachement, ${ }^{2}$ makes it patently clear that positive role models are a key factor in influencing eventual career choice. Respondents valued enthusiasm, eagerness to teach and motivation in those they were attached to as the most important qualities. It is highly likely that similar factors come into play with respect to influencing foundation doctors in choosing to pursue a career in psychiatry. Therefore, it is critical that those of us who are fortunate enough to supervise students and recently qualified doctors are fully conscious of our powers to positively influence recruitment. With great power comes great responsibility, as the saying goes, so the future of our specialty lies in our own hands. 